\title{
VÍAS DE PROTECCIÓN DE LA CREACIÓN DE PROGRAMAS INFORMÁTICOS
}

\author{
RAMÓN TEROL GÓMEZ \\ Becario de Investigación \\ Area de Derecho Administrativo
}

\section{Sumario:}

I. La protección jurídica de los programas de ordenador

I.1. Introducción

I.2. Justificación de su protección

I.3. Antecedentes y evolución

I.3.a) La exclusión de la patentabilidad

I.3.b) El origen de la cuestión

I.3.c.) Derecho internacional y comparado

I.4. La Ley 22/1987, de 11 de noviembre, reguladora de la Propiedad Intelectual

I.4.a) El derecho de autor en general

I.4.b) Peculiaridades del derecho de autor en lo que a programas de ordenador se refiere

I.5. La protección civil del derecho de autor

I.6. La protección penal del derecho de autor

II. La producción de programas de ordenador en el seno de una relación laboral

II.1. Régimen general

II.2. Aplicación del artículo 51 de la Ley de Propiedad Intelectual a la creación de programas de ordenador

III. El Registro de la Propiedad Intelectual. Significado en relación con los programas de ordenador

IV. El concepto legal de programa de ordenador. Relevancia para su protección jurídica 


\section{LA PROTECCIÓN JURÍDICA DE LOS PROGRAMAS DE ORDENADOR}

\section{1. Introducción.}

Cuando se aborda el tema de las nuevas teconologías, y concretamente las informáticas, hay que comenzar haciendo una distinción básica: la diferencia entre software y hardware. Así, vamos a entender por software - o soporte lógico-a las instrucciones o programas de funcionamiento que se dan al ordenador, y por hardware - o soporte físico- a las máquinas u ordenadores electrónicos ${ }^{1}$, todo ello con la finalidad de indicar, desde ya, que el bien objeto de protección al que aquí y en lo sucesivo nos referiremos es el software.

\section{I.2. Justificación de su protección.}

Los programas de ordenador es sabido que son bienes inmateriales que requieren protección o tutela jurídica por idénticas razones de justicia y de -cómo nopolítica económica, que las invenciones o las obras literarias o artísticas, protegidas respectivamente por las patentes o propiedad industrial y por el derecho de autor. El conjunto de instrucciones que conforma cada programa, dirigidas a conseguir un resultado determinado a través de su ejecución por el ordenador, son fruto del ingenio humano, y aunque requiera de un soporte físico no se confunde con él sino que es susceptible de operar simultáneamente en un número indefinido de ordenadores o de estar almacenado en un número de copias igualmente indefinido. Precisamente por ello, surge la necesidad de otorgar una proteción eficaz tanto a los programas como a sus creadores.

En efecto, y como bien señala Karjala ${ }^{2}$, «la facilidad de copia es lo que proporciona, por tanto, las bases de política del Derecho para distinguir los programas de ordenador de las tecnologías más tradicionales. Hay universal acuerdo sobre que la protección legal contra la copia literal de los programas está justificada, y hay acuerdo casi tan universal sobre que una ley del tipo de la del copyright ${ }^{3} \longrightarrow$ que proporciona protección por la mera creción y con un mínimo de formalidades y costoses el camino más apropiado para llevar a cabo tal protección».

'Sobre la relevancia jurídica de la distinción, vid. Pérez Luño, Antonio Enrique, Nuevas Tecnologías, sociedad y Derecho. El impacto socio-jurídico de las N. T. de la información, ed. Fundesco, Madrid, 1987, pag. 26.

${ }^{2}$ Karjala, Dennis, «Copyright, Computer Software, and the new proteccionism», en Jurimetrics, $\mathrm{n}^{\circ}$ 28, 1 (fall 1987), pag. 40, citado por Delgado Echeverría, Jesús, «Comentarios a la Ley de Propiedad Intelectual», dirigidos por R. Bercovitz, edit. Tecnos, Madrid, 1989, pag. 1.321.

${ }^{3}$ Sin detenernos en la exacta traducción del vocablo anglosajón, para nosotros debe entenderse como referido a los derechos de autor. 
Aunque compratimos plenamente lo manifestado por el citado autor, no está de más indicar que para la protección jurídica de los programas de ordenador, del software, se han propuesto dos vías: a través de la patente de invención y por el derecho de autor. Así las cosas, vamos a dedicar las siguientes líneas a justificar la opción por esto último.

\section{I.3. ANTECEDENTES Y EVOLUCIÓN.}

\section{3. a) La exclusión de la patentabilidad.}

La protección de los programas de ordenador por el Derecho de autor se ha producido al comprobarse la insuficiencia de la protección que las patentes les dispensaba. Así, primero la jurisprudencia, y luego las legislaciones más avanzadas, excluyen la patentabilidad de los mismos. Las razones esgrimidas, o por lo menos las más importantes, son las siguientes:

1. La imposibilidad de reunir información suficiente para conocer «el estado de la técnica» en materia de software, lo que hace inviable la realización del Informe sobre el estado de la técnica, y más aún el examen de novedad y actividad inventiva (cosa de la que carecen la mayoría de los programas de ordenador, a juicio de Delgado Echeverría ${ }^{4}$ ) que han de evacuarse para otorgar la protección por la vía de patente ${ }^{5}$. Por ello, en nada satisface a los beneficiarios la cumplimentación de los requisitos que cada patente exige, como, además de los antes vistos, la de registrar el invento con documentación tan detallada que cualquier técnico pudiera realizar industrialmente la invención.

2. La carencia del requisito del carácter industrial del software. Esto lo explica brillantemente Galán Corona ${ }^{6}$ al indicar que «la utilización de las fuerzas de la naturaleza como nota distintiva del carácter industrial de la invención ha de complementarse con el dato de que tal utilización ha de ser objeto directo de la regla para el obrar humano y que tal utilización produce también directamente un resultado material y concreto. Esta inmediatividad medios-fines permite excluir del ámbito de las invenciones patentables aquellas reglas en las cuales la solución del problema reivindicado ya ha tenido lugar antes de que se proceda a la utilización de las fuerzas de la naturaleza», pues el programador «se limita a expresar en instrucciones accesibles al ordenador la solución contenida en el algoritmo, que es la auténtica aportación. Su utilización en el ordenador no altera esta afirmación toda

${ }^{4}$ Vid. Delgado Echeverría, Jesús, «Comentarios...», op. cit., pag. 1.323.

${ }_{5}^{5}$ Esto lo señala Vicent Chulia, Francisco, Compendio Crítico de Derecho Mercantil, Tomo I, Vol. 2 , Ed. J. M. Bosch, 1991, Barcelona, pags. 1.303 y 1.304.

${ }^{6}$ Vid. Galán Corona, Eduardo, «En torno a la protección jurídica del soporte lógico», en Informática e Diritto, $\mathrm{n}^{\circ} 2$, Pavía (Italia), 1983, pags. 60 y 61 . 
vez que el empleo de fuerzas que ello implica tiene lugar después, la solución al problema ya está dada.» La consecuencia de esto es que el programa de ordenador, software o soporte lógico, constituye una regla para el obrar humano que contiene una mera elaboración intelectual, y, por ello, no patentable.

De todas formas, cabe un único supuesto en nuestra legislación por el cual el programa de ordenador sería patentable: como componente de un procedimiento de fabricación o de un aparato protegido por patente o por modelo de utilidad, y exclusivamente para la aplicación del mismo7.

\section{I.3. b) El origen de la cuestión.}

Es indudable que hace tan sólo un par de décadas el desarrollo del software no era importante ${ }^{8}$, siendo a partir de finales de los 60 , cuando entran en juego, primero en el mercado norteamericano, compañías de software independientes de los grandes fabricantes. Así, la importante IBM se vio obligada a abandonar, ya en 1969, la práctica de comercializar el soporte lógico como accesorio de las máquinas, con precio unitario, por ir en contra de la legislación anti-monopolio.

La protección jurídica del software no se hizo esperar, y, como no podía ser de otra manera, comenzó a tener desarrollo en los Estados Unidos, que fue el primer país en incorporar la cuestión a su legislación, aprobando, el 19 de octubre de 1976, el primer texto legal que, ocupándose del problema, lo direccionó hacia los derechos de autor.

\section{I.3. c) Derecho internacional y comparado.}

A los norteamericanos se les unieron inmediatamente en Europa los franceses, que por la vía del derecho de autor, y con exclusión de la patentabilidad, procedió a la protección del software con la Ley $85 / 660$, de 3 de julio, que va a ser un espejo en el que se mirará el legislador español ${ }^{9}$.

Sólo destacar ahora que es unánime en Alemania, Japón, Gran Bretaña e Italia, además de los ya citados, la protección de los programas de ordenador por el derecho de autor.

Visto lo anterior, no es de extrañar que la $\mathrm{OMPI}^{10}$ comenzara a ocuparse de los programas de ordenador. Así, en el contexto de la firma del convenio entre esta organización y las Naciones Unidas (ONU), por medio del cual la OMPI pasaba a

${ }^{7}$ Artículo 96.1 de la Ley 22/1987, de 11 de noviembre, reguladora de la propiedad intelectual.

${ }^{8}$ En Estados Unidos, en 1950, el software suponía sólo un 5 o 10\% del volumen total de producción en el ramo, siendo hoy día aproximadamente del $80 \%$, como indica Vicent Chulia, Francisco, Compendio Crítico..., op. cit., pag. 1.304.

${ }^{9}$ Con mayor profundidad, Vid. Toubol, Frèdèrique, El Software: análisis jurídico, traducidopor Moisset de Espanés, ed. Zavalía, Buenos Aires (Argentina), 1990.

${ }^{10}$ Organización Mundial de la Propiedad Intelectual, WIPO en su acrónimo inglés. 
ser un organismo especializado de la $\mathrm{ONU}^{11}$, se reunió en 1971 un grupo de expertos que provocaron la publicación en 1978, por la Oficina Internacional de la OMPI, de unas «Disposicioes-tipo para la protección del soporte lógico». Estas «Disposiciones-tipo» no eran un Convenio Internacional, ni un borrador de ello, teniendo como intención ayudar a completar las legislaciones internacionales. Así todo, hay que destacar su importancia interpretativa para la comprensión y estudio de las legislaciones de los países miembros de la OMPI ${ }^{12}$.

En lo que a las Comunidades Europeas se refiere, hay que destacar la Directiva del Consejo 91/250/CEE, de 14 de abril de $1991^{13}$, que ordena a los Estados miembros proteger los programas de ordenador mediante derechos de autor. No es previsible por ello que se modifique la Ley que hoy tenemos en vigor en nuestro país, y si así se hace, no comportaría cambios sustanciales que variaran la dirección ya tomada.

\section{I.4. La Ley 22/1987, de 11 de noviembre, reguladora de la Propiedad Intelectual.}

El legislador español, consciente del panorama europeo sobre la materia, y de que la Ley de 10 de enero de 1879 «no podía prever las profundas transformaciones sobrevenidas y, más en particular, las consecuencias del desarrollo de los medios de difusión de las obras de creación que han permitido, por primera vez en la historia, el acceso de los ciudadanos a la cultura, pero que, paralelamente, han facilitado nuevas modalidades de defraudación de la propiedad intelectual» ${ }^{14}$, promulgó la Ley de 11 de noviembre de 1987 para dar a la propiedad intelectual un tratamiento más acorde a nuestros tiempos.

De ella no escapa ni siquiera la novedad que para nuestro fin de siglo supone la creación de programas de ordenador, pero en las líneas siguientes vamos a detenernos en un repaso general a lo que el Derecho de autor supone, pues dentro del mismo se inscribe la protección del bien jurídico que aquí nos interesa: el software.

\section{I.4. a) El derecho de autor en general.}

Espin Cánovas ${ }^{15}$ define el derecho de autor como el «conjunto de facultades inherentes a la persona del autor por el solo hecho de la creación de su obra y las

\footnotetext{
${ }^{11}$ Sobre el régimen jurídico, organización, competencias e importancia dentro de la ONU de la OMPI, Vid.Díezde Velasco Vallejo, Manuel, Instituciones de DerechoInternacional Público, TomoII, ed. Tecnos, Madrid, 1986, pags. 214 y ss.

${ }^{12}$ De la que España es miembro.

${ }^{13}$ Publicada en el Boletín Oficial de las Comunidades Europeas de 17 de Mayo de 1991.

${ }^{14}$ Del preámbulo de la Ley. 1986.

${ }^{15}$ Vid. Espín Cánovas, «El Proyecto de Ley de Propiedad Intelectual de 1986», en La Ley, nº 1.551,
} 
facultades de explotación y disposición libre de la misma». Nos encontramos con un concepto que distingue, acertadamente, dos dimensiones en el derecho de autor: la moral y la patrimonial. Vamos ahora a detenernos en una y otra para ver lo que implican, no sin antes advertir que nuestro ordenamiento jurídico protege a ambas, juntas y por separado ${ }^{16}$.

El derecho moral de autor incluye los derechos de carácter personal, y por ello son definidos como irrenunciables e inalienables. Vienen en los artículos 14 a 16 de la Ley, y son los siguientes:

1. Decidir si su obra ha de ser divulgada y en qué forma.

2. Determinar si ha de divulgar la obra en su nombre, bajo seudónimo o anónimamente.

3. Exigir el reconocimiento de su condición de autor de la obra.

4. Exigir el respeto a la integridad de la obra e impedir cualquier deformación, modificación, alteración o atentado contra ella que suponga perjuicio a sus legítimos intereses o menoscabo a su reputación.

5. Modificar la obra respetando los derechos adquiridos por terceros y las exigencias de protección de Bienes de Interés Cultural.

6. Retirar la obra del comercio, por cambio de sus convicciones intelectuales o morales, previa indemnización de daños y perjuicios a los titulares de los derechos de explotación.

7. Acceder al ejemplar único de la obra, cuando se halle en poder de otro, a fin de ejercitar el derecho de divulgación o cualquier otro que le correspopnda.

Todos estos derechos son ejercitables por el autor durante su vida, excepto los señalados en los puntos 1,3 y 4 , que pueden ser, además, ejercitados por otras personas en determinadas condiciones.

El llamado derecho patrimonial de autor es el que se refiere a la explotación de la obra y se regula en los artículos 17 a 23 de la Ley. Comprende la explotación de la obra en sentido amplio así como los derechos de reproducción, distribución, comunicación y transformación de la misma. Desde luego, no nos encontramos ante un numerus clausus de facultades pues el artículo 17 hace referencia a «explotación de su obra en cualquier forma y, en especial...», de ahí que muchos autores le llamen al derecho patrimonial de autor simplemente de explotación.

Lo destacable de estos derechos patrimoniales es que son todos transmisibles mortis causa e intervivos - son objeto de comercio-, quedando limitada la cesión del derecho o derechos cedidos a las modalidades de explotación expresamente previstas y al tiempo y ámbito territorial que se determinen. Además, la protección

\footnotetext{
${ }^{16}$ Esta disociación viene reconocida por la Ley, que en su artículo 2 dice que «la propiedad intelectual está integrada por derechos de carácter personal y patrimonial».

Asímismo, la Jurisprudencia del Tribunal Supremo viene pronunciándose en la misma línea en sus Sentencias, por poner algún ejemplo, de 19 de enero de 1990 (Ar. 446) y de 19 de julio de 1989 (Ar.5725).
} 
que se dispensa alcanza al «titular de los derechos reconocidos en esta Ley» ${ }^{17}$, lo que implica que pueda tratarse de alguien distinto del autor.

\section{I.4.b) Peculiaridades del derecho de autor en lo que a programas de ordenador} se refiere.

Si bien no es muy discutible la aplicación de lo referente a los derechos patrimoniales de autor cuando la obra objeto de protección es un programa de ordenador, en lo referente a los derecho morales hay que introducir determinados matices, pues a nadie escapa que nos encontramos ante obras que se valoran y distinguen unas de otras por su eficiencia tecnológica, y no por ser expresión de una personalidad individual o por el contenido intelectual que pueda transmitir a su destinatario humano. Son, por tanto, y en su mayoría, obras de escasa originalidad ${ }^{18}$, pues la impronta en ellas de un trabajo personal es poco perceptible.

Una comparación podría hacerse, de entre el resto de objetos de protección de la Ley, con las obras científicas, pero la diferencia también es clara: los programas pretenden resultados técnicos, «no describen cómo conseguir resultados técnicos, sino que son el instrumento para conseguirlo» ${ }^{19}$.

Así, no es de extrañar que el artículo 95 de la Ley indique que a los programas de ordenador se les aplicará lo que indique el Título VII (arts. 95 a 100) y «las disposiciones que resulten aplicables de la presente Ley». Por ello, creemos, al igual que Delgado Echeverría ${ }^{20}$, que con esto se quiere decir que las normas señaladas son un «derecho singular» para los programas de ordenador, respecto de la regulación general del derecho de autor.

\section{I.5. La protección civil del derecho de autor.}

Los artículos 123 a 128 de la Ley se ocupan de las acciones que pueden ejercitarse para proteger los derechos que la misma reconoce. Estas giran en torno a dos finalidades: el cese de la actividad ilícita y la indemnización de los daños morales y materiales que se hayan causado por el infractor. Son ejercitables ante la Jurisdicción Civil y prescriben a los cinco años desde que se cometió la infracción, pudiéndose solicitar las medidas cautelares que la Ley establece ${ }^{21}$.

\footnotetext{
${ }^{17}$ Artículo 123 de la Ley.

${ }^{18}$ Con ello queremos decir que en un programa de ordenador no encontramos una impronta 0 peculiaridad que identifique a su autor, como puede ocurrir en una obra literaria.

${ }^{19} \mathrm{Vid}$. nota 2.

${ }^{20}$ Delgado Echeverría, Jesús, en «Comentarios...», op. cit., pags. 1.343 y ss.

${ }^{21}$ Vid. artículos 126 y 127 de la Ley.
} 


\section{I.6. La protección penal del derecho de autor.}

La Ley Orgánica 6/1987, de 11 de noviembre ${ }^{23}$, que se aprobó junto a la antes referida, modificó el Código Penal dando una nueva redacción a los artículos 534 bis a) y siguientes.

El bien jurídico protegido «tiene una doble manifestación representada por los aspectos moral y patrimonial, cada uno de los cuales comprende un haz de facultades, como son: entre las inherentes al primero, la de publicar o no la obra, defender su paternidad intelectual y su integridad así como el plagio, y entre los comprendidos en el segundo, todas aquellas ligadas a los intereses económicos del autor, como son la distribución, comunicación y transformación de la misma» ${ }^{24}$.

Aclarado lo anterior, con la reforma se castigan, penalmente, la reproducción, plagio, distribución, comunicación o transformación de la obra sin autorización del titular, intencionadas, con multa de 30.000 a 600.000 pesetas y arresto mayor (privación de libertad de un mes y un día a seis meses). En el caso de delito agravado por la concurrencia de alguna de las circunstancias que enumera el artículo 543 bis b), apartado $1^{25}$, podrá recaer la pena de multa de 50.000 a 1.500 .000 pesetas y prisión menor (de 6 meses y un día a 6 años). Si resulta agravado el delito por las circunstancias del apartado $2^{26}$, la pena será de prisión menor y multa de 50.000 a 3.000 .000 de pesetas.

A todo ello se acompaña la posibilidad de publicar la sentencia condenatoria en un diario oficial y de solicitar las medidas cautelares que prevé la Ley de Propiedad Intelectual.

\section{LA PRODUCCIÓN DE PROGRAMAS DE ORDENADOR EN EL SENO DE UNA RELACIÓN LABORAL}

\section{II.1. Régimen general.}

La antigua Ley de la Propiedad Intelectual de 1879 carecía de un precepto que regulara esta situación. Sólo se dispuso, a partir de 1944, del artículo 31 de la Ley de Contrato de Trabajo, también derogado por la vigente Ley de 1987, que con su

\footnotetext{
${ }^{22}$ En mayor profundidad, Vid. Cobo del Rosal y otros, Derecho Penal, parte especial, ed. Tirant lo Blanch, Valencia, 1988, pags. 894 y ss.

${ }^{23}$ Publicada en el B.O.E. de 17 de noviembre de 1987.

${ }^{24}$ Sentencia del Tribunal Supremo de 13 de octubre de 1988 (Ar. 7912).

${ }^{25}$ Animo de lucro, infringir el derecho de divulgación del autor, usurpar la condición de autor o modificar sustancialmente la obra sin autorización.

${ }^{26}$ Especial transcendencia económica y gravedad del daño causado.
} 
artículo 51 establece una norma especial para el supuesto de hecho al que vamos a enfrentarnos: la creación intelectual en el marco de una relación laboral. De esta manera, no cabe hablar de «invenciones laborales» de las reguladas en la Ley de Patentes ${ }^{27}$, pues no nos referiremos ya a la propiedad industrial sino a la intelectual.

La norma del artículo 51 de la Ley de Propiedad Intelectual establece, esquemáticamente, el siguiente régimen:

1. Respeta el principio de autonomía negocial al establecer, en primer lugar, que se estará a lo pactado entre empresario y trabajador (párrafo 1).

2. Si nada se pacta, el empresario adquiere los derechos de explotación -que se entienden transmitidos por el trabajador - en coherencia con su derecho a los frutos reconocido en la normativa laboral vigente (párrafo 2).

3. La actividad habitual del empresario marca el alcance de la transmisión.

En el caso 1 hablaremos de cesión convencional (pacto entre empresario y trabajador) y en el 2 de cesión legal (a falta de pacto). Por ser el supuesto común en toda relación laboral la carencia de pacto expreso, vamos a centrarnos en el segundo supuesto.

Observamos que con la regulación antes expuesta ${ }^{28}$, es discutible la especialidad de la norma por cuanto no se aparta del régimen general del Estatuto de los Trabajadores, cosa en nada objetable pues una regulación diferenciada o que se aparte del principio general de que «los resultados del trabajo por cuenta ajena en régimen de dependencia son del empresario» crearía un agravio comparativo con el resto de los asalariados y sería contraproducente.

Así, será aplicable la cesión legal que se realice entre empresario y cualquiera de sus trabajadores, esto es, aquellas personas que trabajen por cuenta ajena en régimen de dependencia, cuando constituye su vínculo contractual una relación laboral, regulada por el Estatuto de los Trabajadores.

Pero además de la relación laboral entre empleador y empleado, es preciso que haya una conexión o una adecuación material entre la obra creada por el trabajador y el negocio del empresario. Aunque se realice con medios del empresario y se cree en horas de trabajo, la obra que escape de la actividad habitual del empresario no puede entenderse comprendida en el régimen de transmisión legal de derecho económicos establecido por el artículo 51.2.

Con la cesión legal, se entienden cedidos los derechos de explotación, es decir, todos aquellos que permiten la explotación normal de la obra. Pero en todo caso, y al hilo de lo que hemos dicho en el párrafo anterior, sólo son cedidos los derechos

\footnotetext{
${ }^{27}$ En el mismo sentido, Sala Franco, Tomás, Derecho del Trabajo, ed. Tirant lo Blanch, Valencia, 1989 , pags. 543 y 544.

${ }^{28}$ Con más detalle, Vid. Rodríguez Tapia, José Miguel, en «Comentarios...», op. cit., pags. 706 y ss., de ineludible consulta.
} 
de explotación que sean necesarios para el ejercicio de la actividad habitual del empresario.

En cuanto al ejercicio de las acciones que recoge la Ley de Propiedad Intelectual para la defensa de los intereses del titular de los derechos de autor infringi$\operatorname{dos}^{29}$, parece claro que deben ser ejercitables ante la jurisdicción civil. No obstante, podría pensarse que los tribunales competentes debían ser los del orden social, pues extienden su competencia a todos los conflictos generados como consecuencia del contrato de trabajo ${ }^{30}$. «Por ello, estimar que si la actividad del trabajador o del empresario supone infracción del contrato de trabajo será cuestión, sin duda, que debe resolver el Juez laboral. Sin embargo, creo que apreciar infracción del derecho de autor o adoptar las medidas cautelares para su protección son competencia exclusiva del Juez civil $e x$ artículo $127 \mathrm{LPI} »^{31}$.

La extinción del contrato de trabajo no acarrea necesariamente la extinción del derecho de explotación exclusiva del empresario. Desde la finalidad del contrato de explotación firmado con su trabajador hasta la propia causa de la relación laboral explican que el empresario pueda seguir disponiendo de la obra-objeto después de haberse disuelto la relación laboral. De lo contrario, la inversión quedaría fácilmente excluida y el trabajador con el simple cambio de empresa se llevaría consigo no sólo los conocimientos y experiencia adquiridos en la empresa en la que trabajó, sino los productos que por ley corresponden al empresario.

El derecho de explotación exclusiva sobre la obra, la protección que a la misma dispensa el ordenamiento jurídico, hay que advertir que tiene una duración limitada que el artículo 97 fija en 50 años desde su creación o desde el1 de enero del año siguiente al de su publicación, entendiendo la publicación - arreglo al artículo $4 \mathrm{de}$ la Ley- como divulgación de la obra, es decir, como puesta a disposición del público.

\section{II.2. Aplicación del artículo 51 de la Ley de Propiedad Intelectual a la creación de programas de ordenador.}

Resulta evidente que si consideramos a los programas de ordenador como objeto de propiedad intelectual, es la regulación de la misma la aplicable a cualquiera de las cuestiones que puedan plantearse en relación a los mismos, y por ello ha de serles de aplicación lo dispuesto en el artículo 51 de la Ley de Propiedad Intelectual.

\footnotetext{
${ }^{29} \mathrm{Es}$ conveniente recordar aquí que el infractor puede ser tanto el empresario, como un tercero, e incluso el propio trabajador o autor, que está excluído de todo acto de explotación cuando haya otorgado una cesión exclusiva a otra persona.

${ }^{30}$ Artículo 1.2 del RDL 521/1990, de 27 de abril, que aprueba el texto articulado de la Ley de Procedimiento laboral: «los órganos jurisdiccionales del orden social conocerán de las cuestiones litigiosas que se promuevan entre empresarios y trabajadores como consecuencia del contrato de trabajo».

${ }^{31}$ Rodríguez Tapia, José Miguel, en «Comentarios...», op. cit., pag. 802, cuya opinión compartimos.
} 
Esto lo ha manifestado tanto la doctrina ${ }^{32}$ como las Disposiciones-tipo de la OMPI de 1978 en su artículo 2, apartado $1^{33}$. Igualmente, el artículo 2 de la Directiva comunitaria, a la que ya nos hemos referido, sigue idéntico criterio.

\section{EL REGISTRO DE LA PROPIEDAD INTELECTUAL. SIGNIFICADO EN RELACIÓN CON LOS PROGRAMAS DE ORDENADOR}

La Ley establece el Registro General de la Propiedad Intelectual, que dependiente del Minisetrio de Cultura, tendrá carácter único para todo el territorio nacional, disponiendo de una oficina en cada capital de provincia.

No nos encontramos ante un Registro que hace depender de la inscripción en el mismo la protección que se pueda dispensar al software, siendo sus rasgos característicos los siguientes:

1. No es obligatoria la inscripción en el Registro y sus efectos son los señalados en el artículo 130 de la Ley. Esto es, se presumirá que el que aparezca en el Registro como titular del programa lo es en realidad, teniendo que probar lo contrario el que discuta ese extremo. Así, se produce sólo una inversión de la carga de la prueba. Además, esa presunción no abarca sólo a la personalidad del titular sino también a los propios derechos que allí se inscriban, los cuales se presume que existen «en la forma determinada en el asiento respectivo» ${ }^{34}$.

2. La inscripción no se tiene en cuenta para determinar el inicio del plazo de protección del programa, que en nada es tenida en cuenta por el artículo 97.

Independientemente del Registro, el titular o cesionario en exclusiva del programa de ordenador podrá anteponer a su nombre el símbolo «c», rodeado de un círculo, precisando el lugar y año de divulgación. Esto sigue la práctica anglosajona, y es, simplemente, para indicar en la propia obra que los derechos sobre la misma están reservados, lo cual es altamente aconsejable hacer.

\footnotetext{
${ }^{32}$ Delgado Echeverría, Jesús, «Comentarios...», op. cit., pag. 1.350, al indicar que el programador asalariado adopta «la posición reconocida en artículo 51. De acuerdo con el mismo, se transmiten al empresario los derechos de explotación del programa creado en virtud de una relación laboral».

${ }^{33 "}$ «...cuando el software ha sido creado por un empleado en el ejercicio de sus funciones de empleado, estos derechos pertenecen, salvo estipulación en contrario, al empresario».

${ }^{34}$ Artículo 130.3 de la Ley.
} 


\section{EL CONCEPTO LEGAL DE PROGRAMA DE ORDENADOR. RELEVANCIA PARA SU PROTECCIÓN JURÍDICA.}

El artículo 96 de la Ley entiende por programa de ordenador a «toda secuencia de instrucciones o indicaciones destinadas a ser utilizadas, directa o indirectamente, en un sistema informático para realizar una función o una tarea o para obtener un resultado determinado». La importancia de la frase subrayada reside en que si eso es un programa de ordenador, cuando nos encontremos ante otro que consista en una «secuencia de instrucciones o indicaciones» completamente diferente, habrá que admitir su individualidad e independencia respecto del primero.

En efecto, en la doctrina encontramos definiciones como la que sigue: «un programa de ordenador es un conjunto de órdenes o instrucciones que, siguiendo una lógica determinada, guían o dirigen las actividades del sistema (ordenador), indicándole las acciones u operaciones para lograr el fin deseado ${ }^{35}$. De igual modo, las Disposiciones-tipo de la OMPI, en la parte que dedica a las definiciones, se refiere al programa de ordenador como «conjunto de instrucciones que, una vez trasladado a un soporte descifrable por máquina, pueden hacer que una máquina capaz de realizar tratamiento de la información indique, realice u obtenga una función, una tarea o un resultado $»^{36}$.

Aquí puede surgir, y de hecho ha surgido, el debate sobre si lo que se protege es la forma o el contenido del programa. Creo con Vicent Chuliá ${ }^{37}$ que sin duda el objeto protegido no es la idea o el resultado perseguido, que se encuentra en el mundo de las ideas y por ello es de libre apropiación por todos. Pero tampoco se reduce a la formulación literal del programa, sino que comprende su estructura, secuencia y organización, es decir, su arquitectura. Si esto es diferente de un programa a otro, no podemos hablar de infracción alguna de los derechos de autor sino de dos programas de ordenador diferentes, contando cada uno de ellos con una identidad diferenciada ${ }^{38}$.

\footnotetext{
${ }^{35}$ De la revista Actualidad Informática Aranzadi, en el coleccionable Informática para Juristas, abril 1992, pag. 1.

${ }^{36}$ Artículo 1.

${ }^{37}$ Vicent Chulia, Francisco, Compendio Crítico..., op. cit., pags. 1.306 y 1.307.

${ }^{38}$ En efecto, cortar patrones - por ejemplo - no puede ser exclusivo de nadie pues eso está en el mundo de las ideas. Lo que sí puede variar y ser objeto de protección es el mecanismo que se siga para cortarlos.
} 